\title{
BMJ Global Health Limited understanding, limited services, limited resources: patients' experiences with managing hypertension and diabetes in Cambodia
}

\author{
Bart Jacobs, ${ }^{1}$ Cheanrithy Men, ${ }^{2}$ Maryam Bigdeli, ${ }^{3}$ Peter S Hill ${ }^{4}$
}

To cite: Jacobs B, Men C, Bigdeli M, et al. Limited understanding, limited services, limited resources: patients' experiences with managing hypertension and diabetes in Cambodia. BMJ Glob Health 2017;2:e000235. doi:10.1136/ bmjgh-2016-000235

Received 6 November 2016 Revised 8 May 2017 Accepted 19 May 2017

\section{CrossMark}

${ }^{1}$ Social Health Protection Programme, Deutsche Gesellschaft für Internationale Zusammenarbeit (GIZ), Phnom Penh, Cambodia

${ }^{2}$ Chean and Jaco Consulting, Phnom Penh, Cambodia

${ }^{3}$ Department for Health Systems Governance and Financing, World Health Organization, Geneva, Switzerland

${ }^{4}$ Department of Public Health, The University of Queensland, Brisbane, Queensland, Australia

Correspondence to Bart Jacobs, Social Health Protection Programme, Deutsche Gesellschaft für Internationale Zusammenarbeit (GIZ), c/o NIPH, No.2, Street 289, Khan Toul Kork, P.0. Box 1238,Phnom Penh, Cambodia ; bart.jacobs@giz.de

\section{ABSTRACT}

Introduction Health system responses to the emergence of non-communicable diseases (NCDs) in many Southeast Asian nations, Cambodia included, have been insufficient. Little is known about how people suffering from such conditions behave in constrained contexts. We examined the experience of patients with NCDs as they seek care for their conditions and manage them.

Methods In-depth interviews with 28 purposively selected patients with hypertension and/or diabetes using an interview guide to capture the trajectory followed by interviewees from the development and recognition of symptoms to adherence to treatment. A general outline of major topics to be discussed was used instead of a predetermined list of specific questions.

Results All interviewees had experienced symptoms for a substantial period of time, sometimes many years, before being diagnosed. Initial treatment focused on symptoms instead of underlying conditions, often at considerable financial cost. Following diagnosis, many struggled to take medicines daily for their condition and adhering to the required behaviour changes. Many resorted to complementary medicine. Lack of financial resources was a common reason to discontinue treatment. Many reported loss of income and assets such as livestock and productive land and increasingly relied on others.

Conclusion In order to assist people with NCDs in Cambodia, there is a need for a multipronged approach focusing on communities and healthcare providers. Information campaigns could focus on the timely recognition by communities of symptoms indicative of the conditions, together with instigating demand for routine screening at qualified health providers. Peer support is considerable, and locally adjusted approaches based on this principle should be considered.

\section{INTRODUCTION}

Southeast Asia has witnessed rapid industrialisation and urbanisation, together with significant socioeconomic development. This has resulted in lifestyle changes that translate into a high prevalence of chronic non-communicable diseases (NCDs) ${ }^{1-3}$ Older people make up an increasing proportion of the population and chronic NCD disease burden, often with multiple morbidities from various conditions. ${ }^{45}$

Despite earlier pleas to limit the associated health, economic and social consequences by urgently addressing chronic NCDs in low-income/middle-income countries, ${ }^{6}$ health system responses in many Southeast Asian nations have not been sufficient. ${ }^{7}$ As a result, patients remain at increased risk of (further) impoverishment due to the ongoing healthcare costs associated with NCDs. ${ }^{89}$ Cost of medication is a major reason for non-compliance because of the requirement for lifelong treatment. ${ }^{7}$

While there has been some research into the capacity of the Cambodian health system to respond to the demands imposed by the NCD epidemic, ${ }^{10-12}$ little is known about how people suffering such conditions behave in these constrained contexts. An improved understanding of issues confronting patients with NCDs would allow for better-tailored responses to effectively address the medical and socioeconomic needs associated with NCDs, including access and adherence to treatment. For these reasons this research examines the experience of patients with NCDs as they seek care for their conditions, including recognition of symptoms, care-seeking for diagnosis and treatment, accommodation of diagnosis, mobilisation of resources and social support, and impact of these conditions on livelihoods.

\section{Background}

Cambodia's health sector is comprised of private and public health providers. While the public health sector has been under reform since 1996, the private health sector has expanded largely without regulation over the past 20 years; however, it has highly variable quality and services. The private sector consists of unqualified providers such as 


\section{Key questions}

\section{What is already known about this topic?}

- Similar to other countries in the region, hypertension and diabetes in Cambodia account for an increasing share of morbidity and mortality, but the health system and social health protection schemes are ill-equipped to manage the conditions or provide financial protection for associated costs.

- Earlier studies have focused on health system and social health protection constraints in dealing with these conditions.

- Little is known about the experience of patients with hypertension and diabetes regarding the management of their condition.

\section{What are the new findings?}

- The current study complements these studies by taking patients' perspectives and describing the challenges they face from onset of symptoms to obtaining diagnosis and complying with required treatment and behaviour changes.

- There is a considerable time lag before people are diagnosed with their conditions, frequently a result of failure of health providers to measure blood pressure or screen for blood sugar levels whereby the focus is on symptom management.

- Once diagnosed, people did understand the need for continuous treatment and behaviour changes to cope with the condition, and peers were an important source of information and support.

\section{Recommendations for policy}

- The findings suggest a need to educate the community and health providers about symptoms of chronic non-communicable diseases.

- Health providers both within the public sector and the private sector need to be trained to routinely measure blood pressure and appropriately screen blood sugar levels, and to appropriately manage chronic diseases.

- Engagement of peers in all aspects related to self-management of diabetes and hypertension should be actively promoted and current support built upon. care in the public sector, while $50 \%$ of private providers were found to be unqualified. ${ }^{14}$ In border areas with Thailand and Vietnam, it is not uncommon for Cambodians to seek healthcare in the neighbouring country if the facility is closer or quality perceived to be better. ${ }^{15}$

A nationally representative study conducted in 2010 in Cambodia found a diabetes prevalence of $2.9 \%$, while the figure for hypertension was $11.2 \% .^{16}$ These figures compare relatively favourably with those from other countries in the region (table 1). The 2010 study also found that among people aged 55-64 years, $43 \%$ have never had their blood pressure measured and $80.6 \%$ were never screened for blood sugar levels. Among those known to have hypertension, $45 \%$ took medicine for the condition: $35.3 \%$ of rural residents vs $50.6 \%$ in urban areas. There were no differences by gender. ${ }^{16}$

The Cambodian public health system response to date consists of 10 chronic disease clinics (CDCs), established at seven provincial and three district hospitals, that provide integrated outpatient care for people with diabetes and/or hypertension. Attrition rates at these clinics are considerable: $34 \%$ of patients with diabetes were lost to follow-up over a 3-month period, ${ }^{10}$ and after 24 months $42 \%$ of patients with hypertension had discontinued care at the clinics. ${ }^{17}$ Beside these CDCs, the public health sector appears inadequately equipped to deal with NCDs: an assessment of the rural district health system in three provinces that included two CDCs found that hospitals had quarterly drug supplies that allowed them to treat on average five to seven patients for less than 3 weeks each. Only one province reported receiving budget earmarked for NCD management: US $\$ 1800$ per annum for the district hospitals and US $\$ 2400$ for the provincial hospital. The CDC also reported stockouts of hypertension and diabetes drugs. ${ }^{11}$

The assessment of NCD management at the district

Table 1 Prevalence of hypertension and diabetes in Asia for selected countries using WHO STEP wise Approach to Surveillance

\begin{tabular}{llll}
\hline Country (year of assessment) & $\begin{array}{l}\text { Age range of subjects } \\
\text { in years }\end{array}$ & $\begin{array}{l}\text { Proportion with } \\
\text { hypertension }\end{array}$ & $\begin{array}{l}\text { Proportion with } \\
\text { diabetes }\end{array}$ \\
\hline Cambodia $(2010)^{16}$ & $25-64$ & 11.2 & 2.9 \\
${\text { Bangladesh }(2009-2010)^{38}}^{38}$ & $\geq 25$ & 17.9 & NA \\
\hline Malaysia $(2006)^{39}$ & $30-64$ & 29 & 12.2 \\
\hline Vietnam (2015) & $18-69$ & 18.9 & 4.1 \\
\hline Lao People Democratic Republic (2009) ${ }^{41}$ & $25-64$ & 22.3 & $\mathrm{NA}$ \\
\hline Myanmar (2009) & $15-64$ & 30 & $\mathrm{NA}$ \\
\hline
\end{tabular}

NA, not assessed.

traditional healers and market vendors selling medicine among their wares, as well as qualified providers working from health facilities or conducting home visits, often under dual practice. Contrary to public health providers, private sector providers are geographically very accessible. ${ }^{13}$ In rural Cambodia, only $15 \%$ of patients initiate health system took place in conjunction with an analysis - in the same geographical areas - of the diagnostic and treatment pathways, as well as the degree of financial risk protection provided to people with hypertension and/or diabetes according to existing 
social health protection schemes or an NCD-specific scheme. ${ }^{18}$ The former concerned health equity funds (HEF), a third-party scheme reimbursing public health providers for services rendered to poor people, and community-based health insurance (CBHI), voluntary health insurance schemes for the non-poor informal sector population. The latter included a peer education network (PEN) for people with NCDs, operated by a non-governmental organisation, and CDCs. All schemes aim at facilitating financial access to public health services. This study found that, despite their affiliation to one of the four schemes, $43 \%-68 \%$ of cases with NCDs were not on treatment (vs $15 \%$ for PEN members), only $14 \%-33 \%$ got their NCD medicine from public health facilities, and $80 \%$ considered their financial situation as worrying due to their health condition.

\section{METHODS}

This paper complements two published quantitative studies on Cambodia, ${ }^{11} 18$ as part of a broader research project concerning access to medicines for NCDs in rural Cambodia. The study also took place in the health districts of Baray Santuk (Kampong Thom province, Central Cambodia), Kirivong (Takeo province, in the south-east bordering Vietnam) and Samrong (Oddar Meanchey province, northern Cambodia bordering Thailand). Interviewees for this study were derived from a household survey of adults aged $\geq 25$ years from 7361 randomly selected rural households, in which 1559 adults were reported to live with hypertension or diabetes. Of these 1559 adults, 709 individuals were purposively selected for interview. ${ }^{18}$

Of these 709, 28 interviewees were purposively selected for further in-depth interview, based on their affiliation with selected social health protection schemes or NCD-specific interventions, in different locations. Interviewees' addresses were identified from the previous quantitative survey and following identification and informed consent, interviews were usually conducted close to the location where the interviewee was identified: at home, in the rice field, temple or market-place. Interviews were conducted during November-December 2013.

Based on the experience of the quantitative survey among the 709 interviewees, an interview guide was developed to capture in detail the trajectory followed by interviewees from the development and recognition

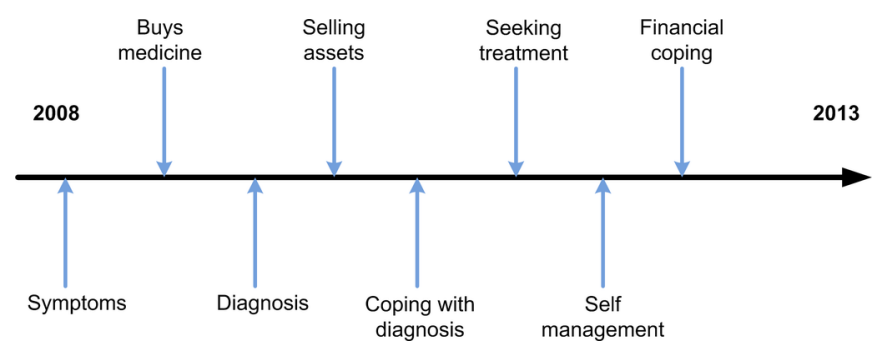

Figure 1 Illustrative timeline of events.

of symptoms, diagnosis, treatment seeking, dealing with diagnosis, lifestyle adjustments, reactions in their social network, impact on livelihood and adherence to treatment. Questions also related to the economic, social and cultural determinants of accessing medicines for their condition.

Each interview lasted between 45 and 90 minutes, depending on the number of events interviewees could recall in detail. Often, family members or friends were present during the interviews, and assisted in providing additional information or helping to remind the interviewee when forgetting some details. All interviews were conducted in Khmer by a native Cambodian researcher trained in the field of medical anthropology.

Initial general questions were asked concerning the sequence of events, enquiring about issues such as 'when did you first become aware of the problem?', 'what were the symptoms and what did you do when they didn't go away?', 'how did you come to know that you have hypertension or diabetes?', 'when and what was your first treatment?'. A timeline was drawn on paper, recording the events sequentially, as described in responses to the general questions. This provided the interviewees with a visual schematic representation that they could amend as the interview proceeded. A simplified illustrative example is shown in figure 1.

During the next step, the event list was used to verify whether all significant events had been recorded. Clarifying questions would take the following form: 'did you use any other medicine or receive other treatments apart from those you mentioned?', 'how did you raise the money to pay for that treatment?' and similar. The primary aim was to understand the sequence of events - not their precise timing. Indications that one event happened 'soon after' another or 'several months later' were seen as adequate for analysis and interpretation, as appropriate representation of the findings required

Table 2 Characteristics of interviewees

\begin{tabular}{|c|c|c|c|c|c|c|c|}
\hline \multirow[b]{2}{*}{ District } & \multicolumn{3}{|l|}{ Condition } & \multicolumn{3}{|c|}{ Scheme } & \multirow[b]{2}{*}{ Indebted } \\
\hline & Hypertension & Diabetes & Both & CBHI & HEF & PEN & \\
\hline Kirivong & 5 & 3 & 1 & 2 & 4 & 3 & 7 \\
\hline Baray Santuk & 5 & 2 & 2 & & 2 & 4 & 6 \\
\hline
\end{tabular}

$\mathrm{CBHI}$, community-based health insurance; HEF, health equity fund; PEN, peer-education network. 
only a reasonable estimate, rather than forcing undue precision. Once the timeline had been established, the interviewer then asked more details on each event to get a more comprehensive picture, including details on the use of coping mechanisms. The interviewer used a general outline of major topics to be discussed, rather than a predetermined list of specific questions.

All recorded interviews were transcribed in the Khmer language and translated into English for analysis. NVivo 10 was used to analyse transcripts. Data were analysed inductively to search for themes, word repetition and local terminology and concepts that emerged from the interviews. Grounded theory approach was used to guide the analysis and interpretation of the data. ${ }^{19}$

\section{Ethical clearance}

Ethical approval was obtained from the Cambodian National Ethics Committee for Health Research (0008 NECHR) and the Research Ethics Review Committee of the WHO (RPC 551). Written informed consent was obtained from literate study participants and verbally from illiterate interviewees. Interviewees were asked whether they wished to be interviewed alone. Despite the interviewer's provision of this option, there was a tendency for respondents to have relatives and/or friends participate in completing the event list, with respondents determining the extent to which individual privacy was maintained during interview. Deidentification was achieved at the point of transcription, with transcribers receiving interview recordings with codes, but no personal identification. Interview codes were also used for analyses of the translated transcriptions. The researcher/ interviewer alone maintained the codebook with the identities of interview recordings and associated codes.

\section{RESULTS}

Of the 28 persons (21 women, 7 men) with NCDs interviewed, 9 resided in Kirivong, 10 in Samrong and 9 in Baray Santuk health district. The median age was 56 years (range 40-82). Fourteen interviewees had hypertension, ten type II diabetes and four both conditions (table 2). Interviewees were aware of their chronic disease for a median of 3 years (range 1-10). Eleven belonged to a social health protection scheme (2 CBHI and $9 \mathrm{HEF}$ ), while nine were enrolled with the PEN. Twenty-two had outstanding debt related to healthcare.

\section{Discovering the disease - from symptoms to diagnosis}

All interviewees had experienced symptoms for a substantial period of time, sometimes many years, before being diagnosed by clinical test or blood pressure measurement at a health facility. Common symptoms reported by interviewees with diabetes included blurred vision, tingling and numbness in hands and legs, weight loss, frequent urination and sleeplessness. For hypertension, reported symptoms included severe headache, stiff neck, dizziness or sleeplessness. The symptom of weight loss was commonly incorrectly perceived as HIV/AIDS.
One way interviewees came to recognise their symptoms before diagnosis was by recognising similar symptoms among other people who were living with or had died from diabetes or hypertension in the family or in the community:

My older brother died because of high blood pressure. I also have high blood pressure. One day, he felt dizzy, numbness in the face, and stiff neck. He began to lie down for a while to feel better and then started working again. When he arrived home, he got upset with his child and then started hitting his child with a coat hanger. After dinner, he went to bed, and when he got up, half of his body could not move. (Hypertension interviewee, Kirivong)

As interviewees continued to experience symptoms over time without diagnoses, or with failure to treat them successfully, they often attributed these symptoms to other diseases or even to supernatural events:

I have felt sick since I was in Phnom Penh, now I am working in the farm here in Kampong Thom. I continued to feel very sick. Some people in the village thought that I must have done something wrong to the local spirits. But I know it is not the case because I have been sick like this for a long time. I got better for a while when I treated myself with the pills, but the symptoms go up and down. Then I started to feel dizzy constantly and my neck was stiff. My brother-in-law saw my condition; he then took me to get the blood test. So, I knew that I have hypertension since last year. (Hypertension interviewee, Baray Santuk)

Without a definitive early diagnosis of the condition, respondents indicated that they coped by treating the symptoms rather than the disease. Most interviewees reported treating their symptoms by using home remedies or traditional medicine, particularly for symptoms such as dizziness, stiff neck, blurred vision, pain and numbness in hands and feet. Modern forms of treatment, especially intravenous infusions, were used to treat symptoms like weakness, tiredness and fainting.

When experiencing severe symptoms, some interviewees sought relief at private hospitals in the capital city or abroad, often without receiving a diagnosis. Some interviewees were only diagnosed once they developed complications and required hospitalisation. The absence of diagnosis also complicated their financial situation, as many spent considerable amounts of money on treating their symptoms, mostly at private clinics, before they came to know their disease diagnosis and current health status. Some mentioned selling assets and borrowing money for their medical treatment prior to diagnosis. Delays in diagnosis appeared to result from mainly consulting drug sellers such as drug shops or pharmacies, but even when frequenting medical professionals they did not necessarily have their blood pressure measured or blood sugar level screened.

\section{Being diagnosed - coping with the verdict}

Once interviewees were diagnosed with hypertension or diabetes, psychological and social factors played an 
important role in coping with their disease status. One reaction on knowing their diseases status was fear, in Khmer referred to as 'Khlach' or 'Phiey'. For interviewees with hypertension, physical impairment as a result of stroke and sudden death were the major causes of fear, often because of other people's experience with hypertension:

The doctor said I have hypertension. I really don't know what it is. I remembered my neighbour with this disease, when he slept at night he was screaming in pain and when he tried to get up, he couldn't get up because one-side of his body was paralyzed. His family said he had hypertension. So, now that I have this disease, I fear I might be like that. (Hypertension interviewee, Kirivong)

Fear of sudden death raised concerns related to family responsibilities and social relations. Once more, having witnessed people dying from these conditions, some interviewees feared that it could happen to them as well.

Social support from family members was considered essential to overcome initial fears upon diagnosis of the condition. Interviewees reported that they did not face discrimination, but rather received sympathy and understanding from relatives and people in the community. However, some interviewees mentioned that other people were initially afraid of them when they fell ill, but once their disease was confirmed to be hypertension/diabetes, people began to show a sense of care by providing encouragement and social support. Several interviewees reported receiving financial support from relatives and friends for their medical treatment.

Some interviewees came to learn about hypertension/ diabetes in their village by seeking advice for their condition from other people in the community. Most interviewees commented that they were open about their disease status and often talked to others about it during social events.

To cope with the mental distress caused by their condition, some interviewees frequented pagodas (Buddhist monasteries) to seek comfort:

I go to pagoda every day. I never hesitate to go to pagoda. (Hypertension interviewee, Kirivong)

\section{Seeking treatment - shopping around}

When seeking medical treatment, most interviewees started with modern allopathic medicine as their first choice of treatment, and in most cases these medicines were purchased from drug shops, pharmacies or from private qualified providers. Some reported obtaining medicine from drug sellers frequenting pagodas. Most interviewees mentioned that they got treated right away after their diagnosis:

They took my blood and did the test. The doctor told me that the sugar level is high. Then he prescribed me the medicine. I also went to buy the medicine in Phnom Penh. But when I ran out of money to travel to go to Phnom Penh, I decided to buy from the clinic here near the market. I bought the same medicine as the one I bought in
Phnom Penh and take it until now. (Diabetic interviewee, Baray Santuk)

However, as interviewees perceived or felt that their condition did not change or improve following some time on treatment, they thought that their medication was no longer effective or 'correct' (local term 'trov'). In such cases they shopped around for a more effective medicine:

It is not that the medicine is not good, but it is not 'correct' for my disease. My condition is still the same. I have stopped taking it because my stomach cannot take it anymore, and it is not 'correct' for my disease. If I continue with this medicine, it is just a waste of money. (Hypertension interviewee, Samrong)

Some interviewees mentioned that they used traditional medicine in combination with modern medicine thinking it could be more effective or even cure their disease. Most interviewees understood that hypertension or diabetes cannot be cured - only treated - by modern medicine, but believe that there is a possibility that traditional medicine can effect a cure.

One interviewee reported consuming an energy drink (Bacchus) - high in its sugar content $(12 \mathrm{~g} / 100 \mathrm{~mL})$ every day, in combination with her diabetes medicine, as she believed that the energy drink made her feel better and gave her energy to do her everyday tasks.

\section{Long-term treatment and self-management}

Interviewees encountered various financial and psychological challenges in adhering to treatment and self-management of their diseases. Descriptions of the relationship between patient and disease were rich in metaphor. Treatment of hypertension and diabetes requires that patients have to take their medicine daily for the rest of their lives, but also make significant lifestyle changes. Taking medicine every day and having to be constantly aware of their food consumption led some interviewees to label hypertension and diabetes as 'professional diseases', referring to their treatment as a 'job' that the interviewees have to carry out every day, but also implying a sense of agency in terms of self-management:

I now become a professional in taking medicine because I take it every day. So, taking medicine to treat my disease is my profession. (Hypertension interviewee, Kirivong)

Another metaphor interviewees applied to the longterm treatment requirement was 'chhoumnger miyear', with connotations of the disease being a delicate woman who needs to be attended all the time, meaning that the patient is always sick and the disease needs to be taken care of constantly. The daily consumption of medicine for diabetes was depicted by an interviewee as being addicted to drug: like a drug addict, they have to buy and take medicine every day to feel better:

I have to go and find medicine. I cannot live without it. It is like being addicted to a drug. If I don't take it, I don't feel good. (Diabetic interviewee, Samrong) 
All interviewees knew they have to take their medication daily but most reported being unable to do so. This was also the case for the required lifestyle changes.

Reasons for not adhering to treatment included 'I am old and forgetful,' 'I am too busy with daily work,' 'I only take it when I don't feel well,' and 'the medicine is not effective anymore, so I stopped taking it.'

One reason often mentioned for not regularly taking their medicine was lack of money. Some interviewees mentioned that the way they coped was to skip several days taking the medicine until they had the money to buy a new supply.

Some interviewees referred to the long-life treatment of hypertension and diabetes as 'breeding the disease', implying that over time, the disease continues to multiply its demands, eating up all their resources.

\section{Financial burden}

As one interviewee put it: 'no money, no medicine'. However, most interviewees expressed concerns that even if they could not afford to buy medicine for a period, they could not stop taking it over the long term out of fear that their condition would worsen. As a result, many mentioned that they had to find a way to cope with this lack of money.

Most interviewees reported that their household had current debts. Some reported that they borrowed for medical costs, but that they also used the opportunity to borrow for other things, such as purchasing food, equipment, fertilisers for farming, animals to raise, and even for wedding or ritual events. Some reported that their original purpose for borrowing money was for social events and agricultural business, but they also used the borrowed amount for medical treatment. The amount of money borrowed was a median of US\$500 (range US $\$ 50$ US\$2000); however, most interviewees who reported having borrowed money could not tell specifically how much they used for medical-related expenditures.

Most interviewees reported borrowing from microfinance institutions, but also from private moneylenders. The former were preferred as interest rates were lower than those of the latter. Interviewees also mentioned borrowing from friends and neighbours, although these were usually small amounts and for shorter periods.

Many interviewees mentioned support from their children as the main source of money for their medical treatment. They had children working in garment factories and abroad in Thailand who sent them money regularly. Some reported receiving donations from peers worshipping at the pagoda, although such support was rather ad hoc and inconsistent.

Many interviewees expressed a sense of blame on themselves for not being able to generate income in comparison with the period when they were in good health.

Some interviewees mentioned that they belonged to a social health protection scheme, but emphasised how these schemes did not help them to cope with the financial burden. Those who were enrolled with CBHI did not use it for their chronic condition, as they perceived that the scheme was only to be used for hospitalisation or inpatient treatment for other illnesses, not for chronic conditions. Similarly, those belonging to the HEF mentioned that they did not use the scheme entitlements for treatment of chronic diseases. Moreover, since these schemes only operate at public health facilities, they did not find them useful, as they perceived medicines at public health facilities to be ineffective, especially when compared with those at the private pharmacy or clinic. One interviewee enrolled with HEF stated:

I went to the health centre several times to get the medicine for my hypertension. I only have to pay 1000 riel for consultation but not for the medicine. But the medicine seems to be not effective, not correct for my disease. I stopped going there. So, now I buy medicine from the pharmacy. (Hypertension interviewee, Samrong)

Interviewees enrolled with the PEN programme acknowledged that they received good medicine and counselling and social support from other patients through their peer network. However, their perception was that despite the benefits of these arrangements, they remained at risk from financial difficulty, as they still needed to pay out-of-pocket for their medication and tests, as well as travelling expenses.

\section{Impact on livelihood}

The impact of the disease on the livelihood of the interviewees and their households can be quite severe. Many reported loss of income and assets such as livestock and productive land. Others coped by using up their savings, government salaries or selling agricultural products. One interviewee described how his illness has drained his financial resources, which he earned from his government salary and selling his cassava produce:

The money I saved from selling rice and cassava, and from my small salary as commune counsellor. All these earnings are used for treatment of my diabetes, which I have for twoyears already. Recently I borrowed 15,000 Baht (US\$500) for my medicine and other things... Now I only have my rice and cassava, these are my only hope to earn enough money for living and for my medicine. Before I got sick, my livelihood was really good. Now that it has been many years with this chronic condition, it has brought us down. My physical strength is also declining, so I stopped working, not going to the farm anymore. Now I only depend on my children and grandchildren to do the work. It is very difficult; I have nothing and I cannot earn anything. (Diabetic interviewee, Samrong)

The impact of the conditions on livelihood is not only expressed in financial terms but also in relation to social capital and human resources. Many reported that they were not able to work anymore due to their condition. They often reflected back to the time that they were in good health and able to work and were physically stronger compared with their present condition. Some interviewees also mentioned that they were not able to 
travel too far for fear that they might be sick and have no one to help them.

Many were the main breadwinners in the family, but now perceived themselves as a disabled person, unable to work and depending on their children. Many interviewees felt that they put a burden on the family for financial support. Several interviewees coped with such circumstances by accepting that it is inevitable that a human being cannot escape from sickness, old age and death, in line with Buddhist teaching:

It is already difficult that I cannot work to earn money, but it is more difficult to depend on my children to take care of us because they are also poor. So, I do whatever I can to treat my disease. I have to put my feelings down to being normal. Like the rest of the people, we cannot escape from sickness and old age, and being old we must die. When I put my feeling like this, I feel normal. (Diabetic and hypertensive interviewee, Baray Santuk)

\section{DISCUSSION}

Findings from these in-depth interviews indicate that people experiencing symptoms suggestive of hypertension or diabetes lived with them for some time before being diagnosed. Symptoms tended to be extensively discussed with family members in search for the underlying condition, in line with findings by Ovesen and Trankell, ${ }^{20}$ who remarked that in Cambodia issues related to health tend to be family matters. Interviewees seemed to have diverse understandings and experience of these symptoms and their causes, some consistent with accepted medical diagnosis, others well outside that frame. As such, prior to their diagnoses being known, these symptoms tended to be attributed to other illnesses, frequently with serious conditions in mind as illustrated by the lay diagnosis of HIV/AIDS due to the weight loss that can happen with diabetes. In some instances interviewees could recognise their symptoms as indicative of hypertension or diabetes based on the experiences of other people in the family or community who suffered the same conditions or died as a result of their complications. Such information-seeking among peers and family members suggests that raising awareness among community members on symptoms of both conditions may improve earlier diagnosis.

Patients' willingness to openly discuss their symptoms reflects the sense that hypertension and diabetes are conditions that people can reveal to one another, in the family and community, without fearing stigma and discrimination. The tendency of patients to consult their social network for many aspects related to their condition, also after diagnosis, is in line with the Social Organization Strategy Framework, which is based on the recognition that many aspects related to disease diagnosis and acceptance are not solely based on the individual's decision but instead result from consultations with one's social network. ${ }^{21}$ Such interactions, as observed in this study, provide patients the means to gain knowledge about their condition.
Such consultative processes contrast with observations from Korea, where it was observed that people with chronic illnesses did not receive any encouragement from friends or relatives, and as a result were reluctant to discuss associated issues for fear of stigma. ${ }^{22} 23$ In our study the empathy displayed by the community for people suffering from these conditions was often related to experiences among their peers who had suffered dramatic consequences such as stroke. When finally diagnosed, most interviewees developed a sense of anxiety, as they associated the disease with impairment and premature death, common to reports from other Asian countries. $^{22-24}$ These factors - the degree of empathy extended by community members and the anxiety associated with the diagnosis - may explain the high treatment adherence rate observed with the PEN programme during the previous assessment ${ }^{18}$ In that study it was found that $85 \%$ of interviewees with hypertension and/ or diabetes affiliated to the PEN took allopathic treatment for their condition compared with only $32 \%-57 \%$ belonging to HEF, CBHI or CDC.

Despite consulting health providers, the interviewees were often not diagnosed initially with the underlying condition, and simply coped by treating the symptoms rather than the disease itself. Often such treatment consisted of administering injections and intravenous solutions, a very common practice in Cambodia. ${ }^{25}$ As mentioned, most medical consultations in Cambodia take place in the private sector, and the interviews suggest that these practitioners have limited diagnostic skills related to hypertension/diabetes. This necessitates improvement of the knowledge of health providers concerning the symptoms of hypertension and diabetes and training them to incorporate routine screening for these conditions in daily practice.

While interviewees were aware about the requirement to take medicines daily for their condition, many struggled to do so. When treatment did not alleviate or improve their condition as expected, interviewees would perceive the prescribed medicines as ineffective and search for alternatives. Similar to findings from other Asian countries, ${ }^{26}$ many resorted to complementary medicine for their condition, often with the objective of improving the effectiveness of allopathic treatment. Some of our interviewees resorted to traditional medicines as a cure for the condition, having been advised that allopathic treatments were unable to cure, but only prevent the consequences of the disease and prolong their lives. Others, in this case a patient with diabetes, erroneously complemented their treatment with energy drinks high in sugar content.

Lack of financial resources was a common reason to discontinue treatment, as reported from other countries, ${ }^{8}{ }^{28}$ whereby treatments were interrupted until sufficient money was available to restart the course. Although the lack of money constituted a common reason for not adhering to treatment, many were already indebted because of previous care-seeking episodes or treatments. Earlier studies also found that interviewees with 
diabetes and HIV/AIDS fell into debt before being diagnosed. ${ }^{29}$ As reported elsewhere, ${ }^{18}$ existing social health protection schemes for the poor and informal sector population did not offer the required financial protection. This was further compounded by poor perception among the interviewees of the public health sector where the schemes have contractual arrangements for services. Nevertheless, evidence from India found that free provision of antihypertension drugs at public facilities led to high treatment compliance. ${ }^{30}$

Because of the financial constraints coupled to the physical burden from the condition that impaired their ability to work, interviewees increasingly relied on others, for financial support and for caretaking. Caregiving can pose an enormous burden, as suggested by findings from Hong Kong, where primary informal caregivers had a much higher risk of poorer health, anxiety and depression, as well as lower quality of life than non-caregivers. ${ }^{31}$ However, in Buddhist Thailand, no such burden was found, which was attributed to the tradition of daughters especially taking care of parents. ${ }^{32}$

Apart from experiencing difficulties with adhering to treatment for a variety of reasons, interviewees mentioned challenges with complying with the required behaviour changes. This invites the application of the self-regulation model, ${ }^{33}$ which focuses on influences on a person's ability to successfully adhere to new lifestyle requirements imposed by their condition, and appears most appropriate to the rural Cambodian context. This model builds on social cognitive theory, and points to possible interventions by linking individual patterns of learning in part to observation of others through social interactions and experiences. As such, the self-regulation arises from an individual's decisions related to disease management that are influenced by observation of peers and community members rather than tradition and fear. This has been evident in community-based strategies for chronic disease management in Cambodia. In Cambodia, where cultural context is highly pertinent, it may be worthwhile to also consider Buddhist principles and traditions to improve patients' self management of chronic conditions when using this model: Buddhism is the primary religion for $95 \%$ of the Cambodian population. The religion emphasises self-healing and promotes the avoidance or minimisation of harmful behaviours, which in turn stimulates self-management. ${ }^{34}{ }^{35}$ Furthermore, the voluntary networks of community elders associated with the pagodas have been observed to offer supportive environments for inducing and maintaining required behaviour changes. ${ }^{36} 37$

\section{CONCLUSION}

The timeline events presented here of 28 people with diabetes and/or hypertension depict a bleak situation in which patients struggle from the onset of symptoms to find a diagnosis and treatment for the underlying conditions. In this period they often treat symptoms instead with dire financial consequences. Family and peers take up a prominent role in directing patients towards a diagnosis and display considerable empathy. In order to assist people with NCDs to access and adhere to treatment in Cambodia, there appears a need for a multipronged approach focusing on communities and healthcare providers. Information campaigns could focus on communities and health providers to recognise symptoms indicative of the conditions in a timely manner, while health providers could benefit from targeted training on managing hypertension and diabetes. Findings suggest that peer support is considerable, and existing approaches based on this principle could be complemented with reference to Buddhist practices.

Correction notice This article has been corrected since it first published. The open access statement has been amended.

Acknowledgements This research was supported by the Alliance for Health Policy and Systems Research, World Health Organization, with funding from DFID. All statements are solely those of the authors and do not necessarily reflect the views of their employers or grant- making agency.

Contributors BJ and CM conceptualised and designed the study. CM conducted the fieldwork and did the initial analyses of the data and wrote the draft report. BJ wrote the first draft of the manuscript and led on its further development. PSH provided further inputs and revisions throughout the manuscript development process. MB reviewed the manuscript and provided additional input. All authors read and approved the final manuscript.

Disclaimer The author(s) is(are) staff member(s) of the World Health Organization. The author(s) alone is(are) responsible for the views expressed in this publication and they do not necessarily represent the views, decisions or policies of the World Health Organization.

Competing interests None declared.

Patient consent Obtained.

Ethics approval Ethical approval was obtained from the Cambodian National Ethics Committee for Health Research (0008 NECHR) and the Research Ethics Review Committee of the WHO (RPC 551).

Provenance and peer review Not commissioned; externally peer reviewed.

Data sharing statement All data from the study have been published.

Open Access This is an open access article distributed under the terms of the Creative Commons Attribution-NonCommercial IGO License (CC BY-NC 3.0 IG0) which permits use, distribution, and reproduction for non-commercial purposes in any medium, provided the original work is properly cited. In any reproduction of this article there should not be any suggestion that WHO or this article endorse any specific organization or products. The use of the WHO logo is not permitted. This notice should be preserved along with the article's original URL. See: https:// creativecommons.org/licenses/by-nc/3.0/igo

(C) World Health Organization [2017]. Licensee BMJ

\section{REFERENCES}

1. Ramachandran A, Wan Ma RC, Snehalatha C. Diabetes in Asia. Lancet 2010;375:408-18.

2. Dans $\mathrm{A}, \mathrm{Ng} \mathrm{N}$, Varghese $\mathrm{C}$, et al. The rise of chronic noncommunicable diseases in Southeast Asia: time for action. Lancet 2011;377:680-9.

3. Singh RB, Suh IL, Singh VP, et al. Hypertension and stroke in Asia: prevalence, control and strategies in developing countries for prevention. J Hum Hypertens 2000;14:749-63.

4. Prince MJ, Wu F, Guo Y, et al. The burden of disease in older people and implications for health policy and practice. Lancet 2015;385:549-62.

5. World Health Organization. The health of older people in selected countries of the Western Pacific Region. Manila: World Health Organization Office for the Western Pacific, 2014.

6. Beaglehole R, Yach D. Globalisation and the prevention and control of non-communicable disease: the neglected chronic diseases of adults. Lancet 2003;362:903-8. 
7. Mannava P, Abdullah A, James C, et al. Health systems and noncommunicable diseases in the Asia-Pacific Region: a review of the published literature. Asia Pac J Public Health 2015;27:NP1-NP19.

8. Smith-Spangler CM, Bhattacharya J, Goldhaber-Fiebert JD. Diabetes, its treatment, and catastrophic medical spending in 35 developing countries. Diabetes Care 2012;35:319-26.

9. Van Minh H, Xuan Tran B, Tran BX. Assessing the household financial burden associated with the chronic non-communicable diseases in a rural district of Vietnam. Glob Health Action 2012;5:188-92-92.

10. Raguenaud ME, Isaakidis $\mathrm{P}$, Reid T, et al. Treating 4,000 diabetic patients in Cambodia, a high-prevalence but resource-limited setting: a 5-year study. BMC Med 2009;7:33.

11. Jacobs B, Hill P, Bigdeli M, et al. Managing non-communicable diseases at health district level in Cambodia: a systems analysis and suggestions for improvement. BMC Health Serv Res 2016;16:32.

12. van Olmen J, Eggermont $\mathrm{N}$, van Pelt M, et al. Patient-centred innovation to ensure access to diabetes care in Cambodia: the case of MoPoTsyo. J Pharm Policy Pract 2016;9:1.

13. Meessen $\mathrm{B}$, Bigdeli M, Chheng $\mathrm{K}$, et al. Composition of pluralistic health systems: how much can we learn from household surveys? an exploration in Cambodia. Health Policy Plan 2011;26(Suppl 1):i30-i44.

14. World Bank. Cambodia's Rural Health Markets. Phnom Penh, 2013.

15. Jacobs B, Price N. Improving access for the poorest to public sector health services: insights from Kirivong Operational Health District in Cambodia. Health Pol Plan 2006;21:27-39.

16. Oum S, Prak PR, Khuon EM, et al. Prevalence of non-communicable disease risk factors in Cambodia. STEP survey, Country Report. Phnom Penh : University of Health Sciences and Ministry of Health, 2011.

17. Isaakidis $\mathrm{P}$, Raguenaud ME, Say C, et al. Treatment of hypertension in rural Cambodia: results from a 6-year programme. $J$ Hum Hypertens 2011;25:241-9.

18. Bigdeli M, Jacobs B, Men CR, et al. Access to treatment for diabetes and hypertension in rural Cambodia: performance of existing social health protection schemes. PLoS One 2016;11:e0146147.

19. Lingard L, Albert M, Levinson W, Research Q. Grounded theory, mixed methods, and action research. BMJ 2008;337:a567.

20. Ovesen J, Trankell IB. Cambodia and their doctors. A medical anthropology of colonial and pots-colonial Cambodia. Copenhagen: NIAS Monographs 117. Nordic Institute of Asian Studies, 2010.

21. Pescosolido BA. Beyond rational choice: the Social Dynamics of how people seek help. Am J Sociol 1992;97:1096-138.

22. Kang M, Kim J, Bae SS, et al. Older adults' perception of chronic illness management in South Korea. J Prev Med Public Health 2014;47:236-43.

23. Nam S, Song HJ, Park SY, et al. Challenges of diabetes management in immigrant Korean Americans. Diabetes Educ 2013;39:213-21.

24. Mendenhall E, Shivashankar R, Tandon N, et al. Stress and diabetes in socioeconomic context: a qualitative study of urban Indians. Soc Sci Med 2012;75:2522-9.
25. Vong S, Perz JF, Sok S, et al. Rapid assessment of injection practices in Cambodia, 2002. BMC Public Health 2005:5:56.

26. Chacko E. Culture and therapy: complementary strategies for the treatment of type-2 diabetes in an urban setting in Kerala, India. Soc Sci Med 2003;56:1087-98.

27. Hasan SS, Loon WC, Ahmadi K, et al. Reasons, perceived efficacy and factors associated with complementary and alternative medicine use among malaysian patients with diabetes mellitus. $\mathrm{Br} J$ Diabetes Vasc Dis 2011;11:92-8.

28. Lall D, Prabhakaran D. Organization of primary health care for diabetes and hypertension in high, low and middle income countries. Expert Rev Cardiovasc Ther 2014;12:987-95

29. Men C, Meessen B, Pelt MV, Lucas K, et al. "I Wish I Had AIDS": A qualitative study on access to health care services for HIV/AIDS and diabetic patients in Cambodia. Health, Culture and Society 2012;2:22-39.

30. Srikanth J, Kulkarni S. Hypertension in elderly: prevalence and health care seeking pattern in an urban slum of Bangalore City. Int $J$ Recent Sci Res 2015;6:2952-7.

31. Ho SC, Chan A, Woo J, et al. Impact of caregiving on health and quality of life: a comparative population-based study of caregivers for elderly persons and noncaregivers. J Gerontol A Biol Sci Med Sci 2009;64:873-9.

32. Limpawattana P, Theeranut A, Chindaprasirt J, et al. Caregivers burden of older adults with chronic illnesses in the community: a cross-sectional study. J Community Health 2013;38:40-5.

33. Clark NM, Gong M, Kaciroti N. A model of self-regulation for control of chronic disease. Health Educ Behav 2001;28:769-82.

34. Lundberg PC, Thrakul S. Type 2 diabetes: how do Thai Buddhist people with diabetes practise self-management? J Adv Nurs 2012;68:550-8.

35. Lundberg PC, Thrakul S. Religion and self-management of Thai Buddhist and muslim women with type 2 diabetes. J Clin Nurs 2013;22:1907-16.

36. Sasiwongsaroj K, Wada T, Okumiya K, et al. Buddhist social networks and health in old age: a study in central Thailand. Geriatr Gerontol Int 2015;15:1210-8.

37. Stewart O, Yamarat $\mathrm{K}$, Neeser $\mathrm{KJ}$, et al. Buddhist religious practices and blood pressure among elderly in rural Uttaradit Province, northern Thailand. Nurs Health Sci 2014:16:119-25.

38. World Health Organization. Non-communicable disease risk factor survey Bangladesh 2010. Dakha: World Health Organization, 2011.

39. Ministry of Health Malaysia. Malaysia NCD Surveillance 2006: NCD risk factors in Malaysia. Kuala Lumpur: Disease Control Division, Ministry of Health, 2006.

40. Ministry of Health Vietnam. National survey on the risk factors of non-communicable diseases (STEPS). Hanoi: Ministry of Health, 2016.

41. Vongvichith E, Phounsavath S, Vongsamphane C, et al; Report on STEPS Survey on Non communicable diseases risk factors in Vientiane Capital City, Lao PDR. Vientiane: World Health Organization, 2010.

42. World Health Organization. Non-communicable disease risk factor survey Myanmar 2009. New Delhi: World Health Organization Regional Office for South-East Asia, 2011. 